\title{
A CONSUMER LOOKS AT THE FOOD AND DRUGS BILL
}

\author{
Arthur Kallet*
}

It would be an easy and pleasant exercise to catalog the improvements over the present food and drug law in the proposed new bill; for example, the provision for legal food standards, for the supervision of cosmetics, and for the extension of regulation to advertising. But when we finish our list, we still find a bill which, under our politically dominated bureaucracies, actually invites vitiation by the pressure groups it is intended to control.

The entire history of regulation in this field has clearly demonstrated that honest, wholesome, and safe products cannot be expected from private profit-seeking enterprise. It should have been recognized, after a sad quarter century of attempted and ineffectual control, that the production of drugs and the processing of most foods is no proper field for business individualism. If our plutocratic government under democratic forms will not tolerate public ownership, consumers might at least reasonably expect systematic, continuous supervision of manufacture and distribution so thorough that the government itself would be able to assure them an adequately wholesome and safe food and drug supply.

This is impossible under the theory of control accepted by the framers of the bill: that the public welfare can be safeguarded by the discovery of illegal products and their removal from commerce instead of by the forestalling of their production in the first place. ${ }^{1}$ In practice this theory supposes that the seizures of a few packages or bottles ${ }^{2}$ will cause manufacturers to forego the large and easy profits in many illegal products. Inquiry should have been made of criminologists as to the degree of social protection which can be achieved by "punishment" equivalent to taking a few cartridges away from an habitual criminal while leaving him his gun and his liberty. Punishment under the proposed law would amount to exactly this. Our bureaucracies and legal system and the motivations behind both being what they are, judicial actions would in most cases-as at present-be directed against canned chicken and liver pills, not against packers and nostrum makers.

- B.S., Massachusetts Institute of Technology, 1924. Secretary, Consumers Research, Inc. Author with F. J. Schlink of 200,000,000 Guinęa Pigs (1933) and of many periodical articles.

1 The latter is now done (in legal theory) with meat and alcohol.

"Fines would probably be as infrequent and prison sentences as rare under the new law as under the old. 
Even in this day of fast changing economic concepts, the framers of the bill still feared to deprive any individual, however ignorant or otherwise unqualified for great responsibility, of the seemingly sacred right to manufacture vital drugs or complex, pctentially contaminated food products. Any ex-racketeer, barred by law from becoming a beer-runner or bucket-shop proprietor, could, under the proposed bill, legally manufacture hospital ether, digitalis, or Colchicum, or an infant food, without any question as to his special qualification, social responsibility, or the availability of any kind of supervision.

To be sure, provision is made for putting an offending class of manufacturers under permit, but only when the injurious nature of the products concerned "cannot be adequately determined after such articles have entered interstate commerce."3 Although this section appears to be an attempt to reach inside state lines without jeopardizing the constitutionality of the bill, one might almost suspect that the brilliant counsel of the united nostrum manufacturers had written it, so well does it assure immunity to offenders or probable offenders. Imagine a political appointee's daring to clamp the lid on all manufacturers of a class of products because conditions of manufacture in some of the plants seem likely to introduce hazards; to put Squibb or Parke-Davis under permit, for example, in order to control irresponsible producers of digitalis or cod liver oill And what an undertaking to prove that the injurious nature of the products cannot be determined after they have entered interstate commerce! This section would be immeasurably strengthened by adding to it a requirement for the placing of any individual manufacturer under permit after a stipulated small number of offenses, whether or not the injurious nature of his products can be determined after their entry into commerce.

The bill, likewise, would have the courts enjoin commerce in an article involved in repetitious offenses; ${ }^{4}$ but it would not prevent the offending manufacturer from making and distributing other articles. It must be remembered, in considering both these sections of the bill, that the fear of tampering with vested interests which burdened the framers of the bill would bear down a thousand times more heavily on political appointees and socially indifferent courts faced with the execution of their provisions, and would therefore effectively nullify their implied purpose except in rare and flagrant cases that had happened to achieve wide public notice. It requires only the most cursory examination of the acts of officials and courts in comparable cases under the present Food and Drugs Act to see that no other result would be possible.

An alternative regulation, based upon the seemingly proper assumption that there is no greater right to manufacture and sell foods and drugs than to brew beer or to denature alcohol, would require the licensing of every manufacturer of drugs and cosmetics, and every processor and canner of foods for interstate commerce. Exceptions would be granted only on affirmative proof, to be passed upon by a board of

'Food and Drugs Bill, 73rd Cong, Ist Sess., S. 1944, \$r2(a).

Id. \$Ig. 
food or drug technologists (not political appointees) that a product or process involves no slightest hazard to consumers. Licenses would be granted only to individuals possessing the technical knowledge and experience necessary for producing specified products, or to corporations employing such persons in responsible managerial positions, where they would be made strictly accountable, at law, as individ. uals. Freedom of access by the proper officials to plants and to all records would be another requirement in the granting of licenses. Further, such essentials as minimum equipment, sanitation, tests, etc. could be covered.

Every distinct product intended for interstate commerce, as well as the producers thereof, would be subjected to license, thereby preventing from the start interstate trade in illicit foods and drugs and worthless medicines. The bonding of responsible individuals, provision for continuous inspection, and other devices could provide an indispensable degree of control over materials, processes, and products. Such devices would no more interfere with individual liberty than do our present automobile and driver licensing systems and traffic control measures. Furthermore, control could be taken, to a large extent, from technically unqualified judges and placed in the hands of process experts and laboratory workers, where it belongs. It is not believed that this line of control would bring our food and drug supply near perfection; it would, however, afford fair protection to consumers, although it might work hardships on more or less well-intentioned but incompetent entrepreneurs.

A part of the above proposal is embodied in the modification of the administration bill introduced by Congressman Sirovich. Dr. Sirovich would have every packaged drug bear a registered label ${ }^{5}$ - a vast improvement over the general labeling provisions of the administration bill, but still seriously defective in that it would place the approval of labels in the patent office where this function cannot be competently exercised, and decidedly does not belong.

There is probably no more serious defect in the bill than the broad discretionary powers vested in the Secretary of Agriculture. The phrasing of the bill would permit the Secretary to abstain completely from taking regulatory actions along many lines, and no consumers' proceeding in any court could compel him to do more than use his own judgment. The bill, as written, permits him to choose at many important points between the safeguarding of the public and the shielding of food and drug manufacturers. By placing in the hands of the Secretary for final determination the establishment of standards, and such highly technical questions as degree of toxicity, tolerances, and other crucial points of control-casually treated in the bill-the way is opened for a process of attrition by which the industries can break down whatever effectiveness the law may have in the beginning.

There is food for sad reflection in the frenzied energy with which the nostrum manufacturers are already preparing to defeat the bill. Every advertisement sent to newspapers and magazines by many medicine makers is accompanied by the sug-

'73rd. Cong, Ist Sess, H. 6rro (1933). 
gestion that the publication protest the new bill if it wishes to receive more such profitable advertisements. This line of attack is, of course, obvious; but the industry plans to go even to the length of organizing the truckmen who transport the nostrums, the owners of their factories, and everyone else on whom they can lay their hands through related economic interests, to defeat the bill.

Whether or not the pressure they bring to bear succeeds, we are concerned here with the knowledge that, should the bill pass, the same intense pressure will unremittingly be brought to bear on the Secretary of Agriculture for years to come. And in the end, perhaps after three or four administrations have come and gone, the Secretary's power to exempt the industries from many of the regulatory provisions which they most fear would inevitably result in the emasculation of control.

The bill, as written, would rightfully put an end to the wide sale of such nearly worthless preparations as Mercurochrome (in aqueous solution), Listerine, and Lydia Pinkham:s Vegetable Compound. It requires little imagination to visualize the nature of the industry's offensive against such an un-American, communistic, antiRecovery program-the wilful destruction of honest, ethical (and profitable) business; and only slight prophetic gifts to realize that the offensive would succeed.

There is not the remotest possibility that any politically appointed Secretary of Agriculture could long withstand the constant organized clamor from the food and drug industries and their friends in and out of Congress for the lowering of standards, the stealthy increasing of tolerances on toxic substances and adulterants, and the general relaxation of enforcement which the bill, in a dozen different ways, virtually invites. The bill makes possible a repetition of the long series of acts by which the present law was emasculated; for example, the adoption by the Secretary of Agriculture under pressure from the Maine fish packers, of a definition for sardines formulated in a business-fostering bureau of the Department of Commerce instead of in the proper technical bureau of the Department of Agriculture. This decision, made within three months of the effective date of the Food and Drugs Act (January $x, x 907$ ), included in the definition of "sardines" all varieties of small fish similar to genuine sardines. Other decisions, like this one clearly contrary to the intent of the law, permitted the renaming of glucose and cornstarch syrup as "corn sugar" and "corn syrup"; the importation of canned vegetables made artificially green with salts of copper; and the use of benzoate of soda and benzoic acid as preservatives.

While it will of course be said that such yielding to pressure is unlikely under the present Secretary of Agriculture, he recently made a decision far more dangerous to the public welfare than those cited above-which only shows the futility of trusting, in a profit-motivated society, to the resistance to pressure of any public official, however well-intentioned he may be personally.

This decision involved the amount of lead remaining on apples which had been sprayed with lead arsenate insecticide. Ignoring a previous decision (unentorced) by the Chief of the Food and Drug Administration that no lead residue would be 
permitted because of the great hazard from this cumulative poison, the Secretary legalized a residue of fourteen thousandths of a grain of lead per pound of fruit, an amount sufficient to endanger the public health and to contribute to chronic, insidious lead poisoning in many susceptible individuals. This, despite the fact that the residue can be inexpensively removed, either by the growers or by the government. Not even this ruling satisfied the fruit growers, however, and, led by Senator Byrd of Virginia (who is the largest of American applegrowers) and Governor Moore of New Jersey, they exerted sufficient pressure in the proper high places to cause an increase of nearly fifty per cent in the permissible residue.

Nearly all decisions of this kind are technical in nature, not administrative, and should be made by technologists, insulated from outside pressures and influences, and with tenure independent of political control. Whether any lead should be permitted to remain on fruits and vegetables, and if so, how much can be safely tolerated, should be decided by toxicologists, not by a member of the Cabinet or an undersecretary with political or general administrative duties.

A new food and drug bill could provide for nothing more important than the establishment of independent boards of toxicologists without whose unanimous approval no tolerance would be permitted for any poison or suspected poison; whose unanimous approval would also be required for any increase in an official tolerance. The bill leaves the entire question of the determination of what is or may be injurious to health to the judgment of the Secretary who may or may not, at his own discretion, seek competent advice; or, having sought it, may follow or disregard it as he wills. The bill requires no research in the control of food and drug processing or in toxicology; and in no way would it prevent the suppression of commercially undesirable technical findings on poison hazards, the very type of suppression that has been practiced under the present law since the days of Harvey Wiley. Whatever the present Secretary of Agriculture may or may not do with the freedom allowed him in these matters, it is foolhardy to suppose that future secretaries will follow policies based upon consideration for the public good.

Wide, unremitting publicity exposing every violation and every violator of the law is absolutely essential for the protection of consumers. Not only does such publicity provide the public with a defense against the purveyors of illegal products, but it also builds up the public counter-pressure for strict enforcement necessary to combat governmental laxity under business pressure. The likelihood that any considerable volume of effective publicity would result from the publicity section of the bill as now written is extremely slight. The bill provides that "The Secretary shall cause to be disseminated such information regarding any food, drug, or cosmetic as he deems necessary in the interests of public health and for the protection of the consumer against fraud." If the purpose of this section is to be accomplished, the law must make mandatory searching publicity for every phase of every violation from

-Food and Drugs Bill, supra note 3, \$21. 
the laboratory findings to the ultimate disposition of the case. The flow of facts concerning violations must not be a matter of official discretion; for if it is, it can safely be predicted that there will be no publicity except, as now, when very small merchants or producers, in most cases foreigners, are involved. The publicity section of the bill is apparently an attempt to perpetuate the theory of present enforcement officials that it is better to jeopardize the welfare of all consumers than to risk publicity unfavorable to a single large-scale producer who might prove to be quite innocent.

The section of the bill relating to advertising, good as it is in intent, presents an enforcement problem which could not be handled with a staff devoted entirely to this phase of control even if such a staff were several times as large as that which the entire enforcement division is likely to have. Imagine the effort required to police advertising for food, drugs, and cosmetics in newspapers, magazines, radio, billboards, handbills, counter displays, and whatever other media hardpressed and ingenious advertisers can invent, to discover if the advertising "is untrue, or by ambiguity or inference creates a misleading impression. ..."!? Here at last are jobs aplenty for all of the literate unemployed. In appraising the possible effectiveness of such control, it must be borne in mind that not one out of perhaps a thousand advertisements in the field of drugs and cosmetics intended for general consumption is free from untruth, or from ambiguity or inference intended to create a misleading impression.

The difficulty of advertising control would be about halved, though still tremendous, if the framers of the bill had not been frightened by the awful cry of censorship from requiring advance submittal of copy. Newspapers and magazines constantly boast that they censor their advertising. But the suggestion that such censorship be placed in the hands of anyone of actual competence who is not overly concerned about advertising revenues, throws the publishers into a passion over the "freedom of the press." They might better be concerned with the pernicious influence of the advertisers over their news and editorial columns, as evidenced by the flood of apparently inspired editorials condemning the proposed bill.

The control of advertising might be further simplified by requiring the registry of claims to be made for advertised food, drugs, and cosmetics (the American Medical Association does this for food products submitted for its acceptance) and permitting only approved claims to be made. Or, if this would cause too many suicides in the advertising agencies, the advertisers might be permitted to write, recite, or picture what they will, provided every advertisement making any claims whatsoever, also carries the officially accepted and registered claims.

The bill's requirement that formulae be stated on drug labels should be extended to advertising. The framers of the bill would have advertising controlled only because they know that people buy on the strength of the advertising they see or hear,

${ }^{7} I d . \S_{9}$ (a). 
not because of statements on labels. This reasoning should apply to formulae as well as to claims. Here we might follow the good example of the Philippines, where the publication of formulae in drug advertisements is now required by law. ${ }^{8}$

Certainly in is to be hoped that any advertising control finally enacted will not, as is now proposed, exempt advertisements in medical, pharmacological, and scientific publications. Curious as it may seem to some, these publications are also concerned about advertising revenues, and regularly carry their share of ballyhoo for worthless and sometimes dangerous preparations. And, alas, the doctors and druggists are taken in by the advertisers almost as easily as the uninformed layman. A notorious example is the advertising for Mercurochrome which has appeared regularly in the publications of the American Medical Association, despite the fact that the unreliability of this antiseptic in the usual solution has been exposed by a dozen authorities, including the Association's own committee on the subject. Unfortunately, some thousands of physicians who read interestingly worded advertisements but not dry-asdust reports on antiseptics, continue to recommend Mercurochrome to their patients.

Possibly with the hope of using to advantage the torrent of the anti-prohibition sentiment, the medicine makers are losing no opportunity to declare that the proposed bill would deprive ailing citizens of the sacred right of self-medication. This, of course, is nonsense; but the problem of self-medication deserves careful consideration, nevertheless, in the regulation of proprietary medicines. At least until we have socialized medicine, many millions of persons will of necessity continue to diagnose their own minor ailments and to select their medicines. If a new law drives the dangerous and completely worthless nostrums off the market, it will be doing a valuable service for these people. A further and more valuable service could be done by making provision for the certification of a small list of open formula medicines, ${ }^{0}$ safe and reasonably efficacious for self-medication, to be manufactured by qualifying producers under license. Standard precautionary labels and advertisements would, of course, be stipulated.

The framers of the bill apparently assumed that the control of food and drugs should remain in the Department of Agriculture. The danger to consumers in having a control activity at times strongly antagonistic to the interests of food and drug producers in a Federal department intended to promote the distribution and consumption of such products, is evident from the aforementioned decision on lead residue. The only logical place in the existing government services for food and drug control is the Public Health Service. Unfortunately, however, the Public Health Service is part of the Treasury Department, where, it must be admitted, its scientific integrity has suffered grave indignities. If this bureau can be given autonomy and a chance to go straight, food and drug control should by all means be transferred to it.

In any event, there is probably strong justification for such a transfer. Since the Service is under the immediate direction of physicians, it might be possible to have

82 Philippine Penat Code (1930), Act No. 2342, $\$ 3$.

- The formulac would require periodic review by the certifying body. 
foods and drugs controlled by men with a clearer conception of the nature of hazards involved and less concern for business necessities. This transfer has been discussed from time to time during the past several years. The determined and invariable opposition of the food and drug journals is, perhaps, a strong point in its favor. There is, for example, reason for grave suspicion of the manner in which the public is now being protected, when we read such items as the following from the Oil, Paint and Drug Reporter:

Out of long experience, the Department of Agriculture has got a reasonable conception of the economic importance of the act. It has come to a fair measure of recognition of the industrial problems involved in compliance with the law. It is not inconsiderate of the right of manufacturers to be heard and to be informed. Although a more satisfactory administration of the act in certain particulars is possible, the situation could be worse; and it would be worse if the act were administered by the Public Health Service.

In addition to the transfer of control, it would be desirable to define, in the bill, the qualifications of the heads of the control divisions in order to insure technical rather than political competence. It cannot be too strongly emphasized that to be effective, control must be taken out of politics. This ideal can be approached only by precise legislative definition of the qualifications of officials; by the setting-upagain by legislation subject to amendment only by Congress itself and not by discretionary appointment- of independent boards of technologists for the establishment of standards, and the determination of questions of toxicity, tolerances, etc., the decisions of which will be subject to no administrative review.

It is recognized that the proposals briefly sketched in this article would do violence to those "rights" which are considered inalienable by all sound business men. And if our legislators find, after due deliberation, that the food and drug business men must be protected, the consumer can only walk warily until another "new deal" throws private enterprise out of such vital industries altogether. 
